\title{
Uveal Melanoma TNM Finding v8
}

National Cancer Institute

\section{Source}

National Cancer Institute. Uveal Melanoma TNM Finding v8. NCI Thesaurus. Code

C140603.

A finding about one or more characteristics of uveal melanoma, following the rules of the TNM AJCC v8 classification system. This classification system applies to malignant melanoma of the iris, ciliary body, and choroid. Cutaneous melanoma metastatic to the iris, ciliary body, and choroid is staged according to the classification for melanoma of the skin and secondary intraocular extension of conjunctival melanoma is staged according to the classification for conjunctival melanoma. (from AJCC 8th Ed.) 